\title{
Corrigendum: Friendship Quality and Gender Differences in Association With Cyberbullying Involvement and Psychological Well-Being
}

\author{
Mairéad Foody*, Lian McGuire, Seffetullah Kuldas and James O'Higgins Norman \\ National Anti-Bullying Research and Resource Centre, Dublin City University, Dublin, Ireland
}

Keywords: cyberbullying, friendship quality, gender, psychological well-being, post-primary

\section{A Corrigendum on}

Friendship Quality and Gender Differences in Association With Cyberbullying Involvement and Psychological Well-Being

by Foody, M., McGuire, L., Kuldas, S., and O'Higgins Norman, J. (2019). Front. Psychol. 10:1723. doi: $10.3389 /$ fpsyg.2019.01723

OPEN ACCESS

Edited by:

Eva M. Romera,

Universidad de Córdoba, Spain

Reviewed by:

Daniel Falla

Universidad de Córdoba, Spain

*Correspondence:

Mairéad Foody

mairead.foody@dcu.ie

Specialty section:

This article was submitted to

Educational Psychology,

a section of the journal

Frontiers in Psychology

Received: 25 October 2019 Accepted: 11 December 2019

Published: 24 January 2020

Citation:

Foody M, McGuire L, Kuldas S and

O'Higgins Norman J (2020)

Corrigendum: Friendship Quality and

Gender Differences in Association

With Cyberbullying Involvement and

Psychological Well-Being.

Front. Psychol. 10:2931

doi: 10.3389/fpsyg.2019.02931
In the original article, there was an error. Under the Participants section, a previous publication by the first author was written as BLINDED PUBLICATION. This should read as Foody et al. (2019).

A correction has been made to the Materials and Methods section, subsection Participants:

"This study forms part of a wider research project which investigated the prevalence rates of traditional and cyberbullying in Ireland. A brief description of the sample is included here but authors are referred to Foody et al. (2019) for more details on the population and ethical approval. Originally, all post-primary schools in Ireland were invited by email to participate in this study. If interest was noted, the researcher gave more information by email or phone to the principal. Once principals agreed to take part, information and consent forms were sent to the principal to distribute among parents. Principals decided on the classes/age groups to which they would administer the survey, depending on what their own timetable and resources allowed. A final sample of over two thousand participants from 30 different post-primary schools participated $(N=2410 ; 43.2 \%$ males and $56.8 \%$ females) representing $3.7 \%$ of the entire post-primary school population in Ireland. Participants were aged between 12 and 16 years [M(SD): 13.5(1)] and attending 1 st to 3 rd year in schools across the country."

The reference list has also been updated to reflect this correction.

The authors apologize for this error and state that this does not change the scientific conclusions of the article in any way. The original article has been updated.

\section{REFERENCES}

Foody, M., Samara, M., and O'Higgins Norman, J. (2019). Bullying by siblings and peers: poly-setting victimization and the association with problem behaviours and depression. Br. J. Educ. Psychol. doi: 10.1111/bjep.12311. [Epub ahead of print].

Copyright $\odot 2020$ Foody, McGuire, Kuldas and O'Higgins Norman. This is an open-access article distributed under the terms of the Creative Commons Attribution License (CC BY). The use, distribution or reproduction in other forums is permitted, provided the original author(s) and the copyright owner(s) are credited and that the original publication in this journal is cited, in accordance with accepted academic practice. No use, distribution or reproduction is permitted which does not comply with these terms. 